\title{
An update on model Ayush wellness clinic at president's estate, India
}

\begin{abstract}
The Government of India has introduced an increased advocacy of AYUSH system of medicine and establishment of Indian systems of medicine specialty centres. Taking this vision forward, the Rashtrapati Bhavan with help of Ministry of AYUSH, Government of India; established the first AYUSH Wellness Clinic (AWC) of the country at President's Estate in July 2015. The AWC has treatment facilities in the streams of Ayurveda, Yoga and Naturopathy, Unani, Siddha \& Homeopathy.AWC caters to the medical needs of the President, officials of President's Secretariat and residents of the President's Estate. This paper presents an update on the success and the work done at AWC from its inception in July 2015 to January 2018. A total of 82137 patients were consulted and nearly 46443 received various therapies prescribed by the physicians during this time period. AYUSH awareness workshops are being conducted for every year. New initiatives in the year 2015 include establishment of herbal garden at the AWC premises, designated touch screen interactive kiosk and starting Skill-development and Internship Programme for the residents. New initiatives in the year 2016 include Village out-reach programme and participation in the Festival of Innovation at Rashtrapati Bhavan. As new initiative in the year 2017- new therapies were added to the existing services in Ayurveda wing, Yoga and Naturopathy wing and Unani wing; the therapists and support staffs working at AWC were trained in FirstAID and CPR and 22 research papers were published in peer reviewed indexed journals.
\end{abstract}

Keywords: AYUSH wellness clinic, Unani, Sidha, Homeopathy, rashtrapati bhavan, India
Volume II Issue 3 - 2018

\author{
Anjali BM Bakshi,' Tushita Thakur, ${ }^{2}$ Izharul \\ Hasan, ${ }^{3}$ Vinod Kumar Shahi ${ }^{4}$ \\ 'Joint Director, Rashtrpati Bhavan, New Delhi, India \\ ${ }^{2}$ Homoeopathy Consultant, AYUSH Wellness Clinic, President's \\ Estate, India \\ ${ }^{3}$ Unani Consultant, AYUSH Wellness Clinic, President's Estate, \\ India \\ ${ }^{4}$ A.D. (Ay) CCRAS \& Co-ordinating Officer,AYUSH Wellness \\ Clinic, India
}

Correspondence: Anjali BM Bakshi, Joint Director, Rashtrpati Bhavan, New Delhi, India, Email drizharnium@gmail.com

Received: March 05, 2018 | Published: June 042018

\section{Vision and objective}

Honourable Prime Minister of India has created AYUSH ministry in November 2014 by elevation of the Department of AYUSH under Ministry of Health and Family Welfare with the vision to encourage the Indian system of medicine and Homeopathy. The Government of India has emphasised increased advocacy of AYUSH system of medicine and establishment of Indian systems of medicine specialty centres. Taking this vision forward, the Rashtrapati Bhavan with help of Ministry of AYUSH established the first AYUSH Wellness Clinic (AWC) of the country with all the five systems under one roof at President's Estate in July 2015. A dilapidated building in the President's Estate was renovated and converted into the AWC. The AWC has treatment facilities in the streams of Ayurveda, Yoga and Naturopathy, Unani, Siddha \& Homeopathy. The clinic caters to the medical needs of the President, officials of President's Secretariat and residents of the President's Estate. ${ }^{1,2}$

\section{Our mission}

Our mission is achieving and maintaining excellence in healthcare services through Indian system of medicine and Homoeopathy. We provide comprehensive healthcare services to our valued beneficiaries in form of consultations and therapy through our Ayurveda, Yoga and Naturopathy, Unani, Siddha \& Homeopathy OPDs. Along with consultation, medicine, and therapies; disease prevention and positive health promotion services are also provided at AWC.

\section{Organisation and infrastructure/ administration}

Manpower including consultants, therapists and MTS staff is being provided by M/O AYUSH, Government of India. The Staff for maintenance, cleanliness and security is being provided by Rashtrapati Bhavan. The infrastructure \& equipment is provided by Rashtrapati Bhavan and medicines are provided by M/O AYUSH, Government of India. ${ }^{3}$

\section{Service delivery mechanism}

Patient data is maintained by the special clinic software designed by National Informatics Centre, Ministry of Electronics and IT, Government of India. Automatic OPD cards are generated by entering patient details. The detail of diagnosis and medicine/therapy prescribed is entered into the software by consulting physicians. ${ }^{4}$

\section{Human resource}

The committed human resource working at the clinic includes one male and one female physician in all five wings namely Ayurveda, Yoga and Naturopathy, Unani, Siddha \& Homeopathy. Ayurveda, Yoga and Naturopathy, Unani and Siddha wings have one male and one female therapist. Yoga and Naturopathy wing has an additional Yoga therapist. Besides this, all wings have one male and one female MTS and all except Yoga and Naturopathy have a pharmacist. ${ }^{4}$

\section{Overview of patients receiving services}

An overwhelming number of patients have benefitted from the healthcare services being provided at AWC. The overview of the beneficiaries from January to December 2017 is given below in Table 1 \& Table 2, (Figures 1-7). 
Table I Overview of Patient Consulted from July 20I5-January 2018

\begin{tabular}{llllll}
\hline \multirow{2}{*}{ Department } & \multicolumn{2}{c}{ New patient cases } & \multicolumn{2}{c}{ Follow up cases } & Total \\
\cline { 2 - 5 } & Male & Female & Male & Female & \\
\cline { 2 - 5 } Ayurveda & 4431 & 2739 & 6690 & 4864 & 18724 \\
Yoga and Naturopathy & 1476 & 1295 & 5263 & 5083 & 13117 \\
Unani & 3829 & 3126 & 5850 & 6521 & 19326 \\
Sidha & 1812 & 1428 & 3450 & 4165 & 10855 \\
Homeopathy & 4338 & 4237 & 4966 & 6542 & 20083 \\
Grand Total $=$ & 15886 & 12825 & 26219 & 27175 & 82137
\end{tabular}

*Sourced from NIC special clinic software ${ }^{5}$

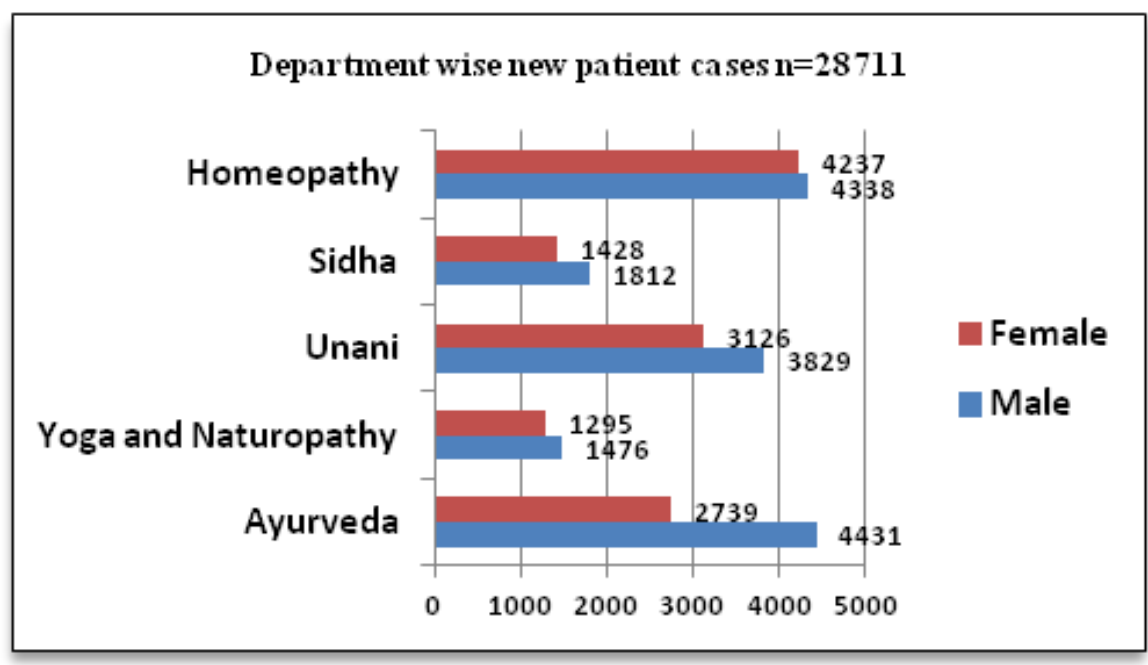

Figure I Department wise new patient cases (July 20I5-January 20I8).

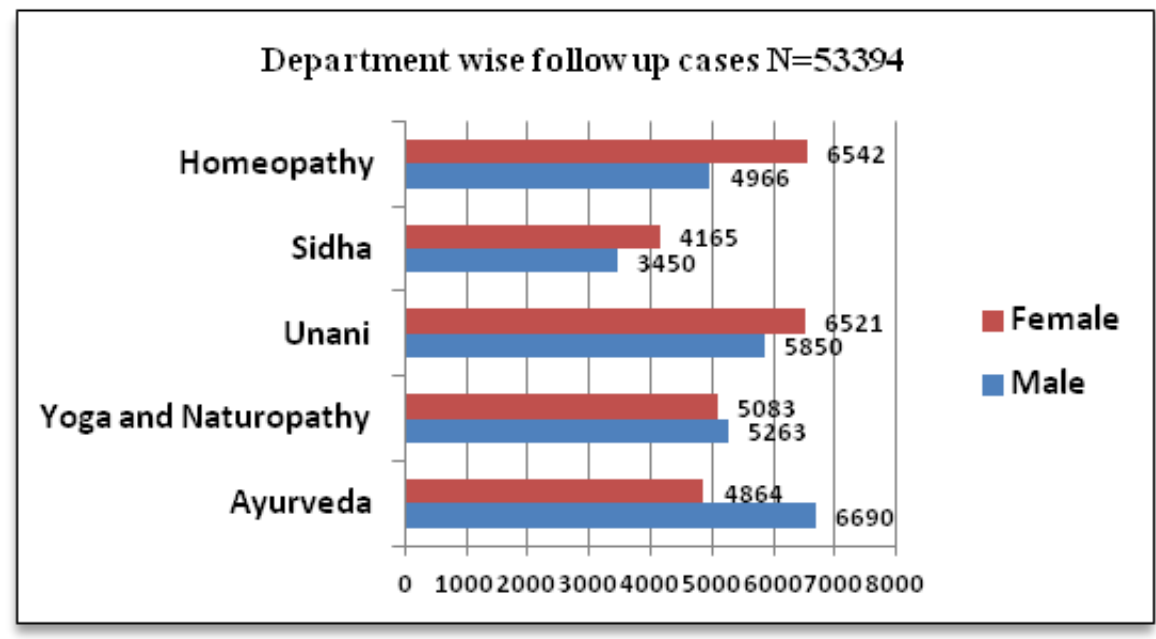

Figure 2 Department wise follow up patient cases (July 20I5-January 20I8). 


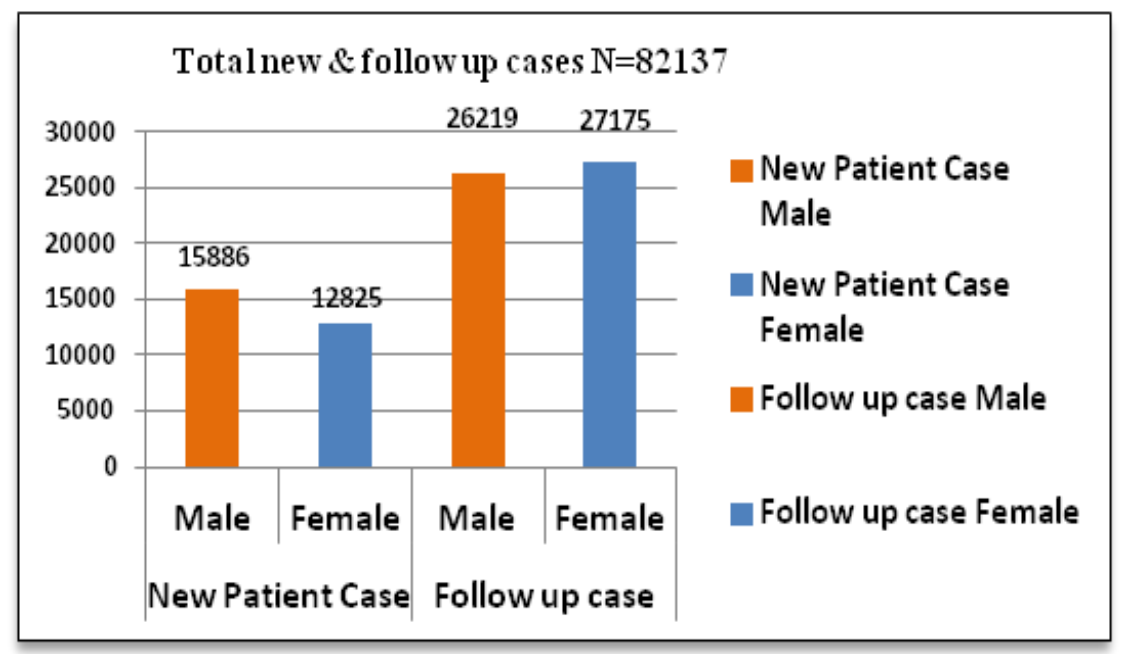

Figure 3 Total new and follow up cases (July 2015-January 2018).

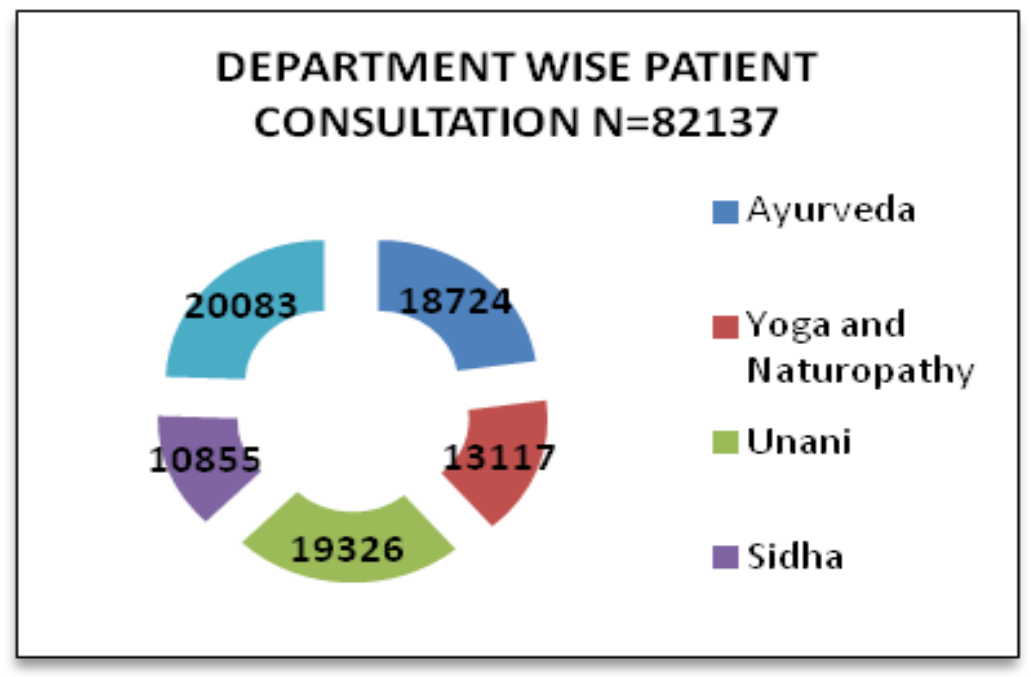

Figure 4 Pie chart of department wise consultations (July 20I5-January 20।8).

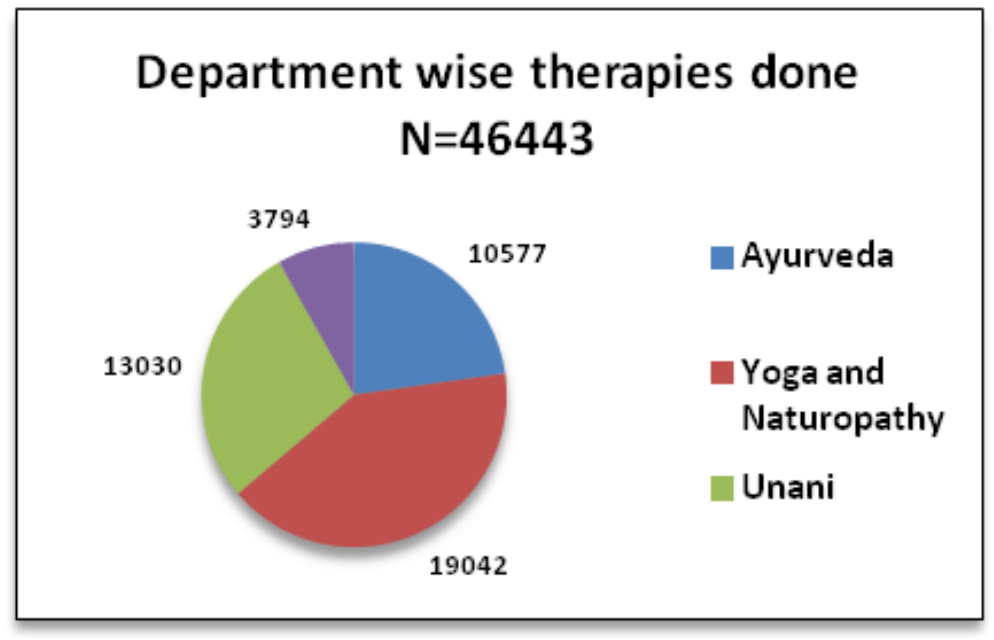

Figure 5 Department wise therapies done (July 2015-January 2018). 


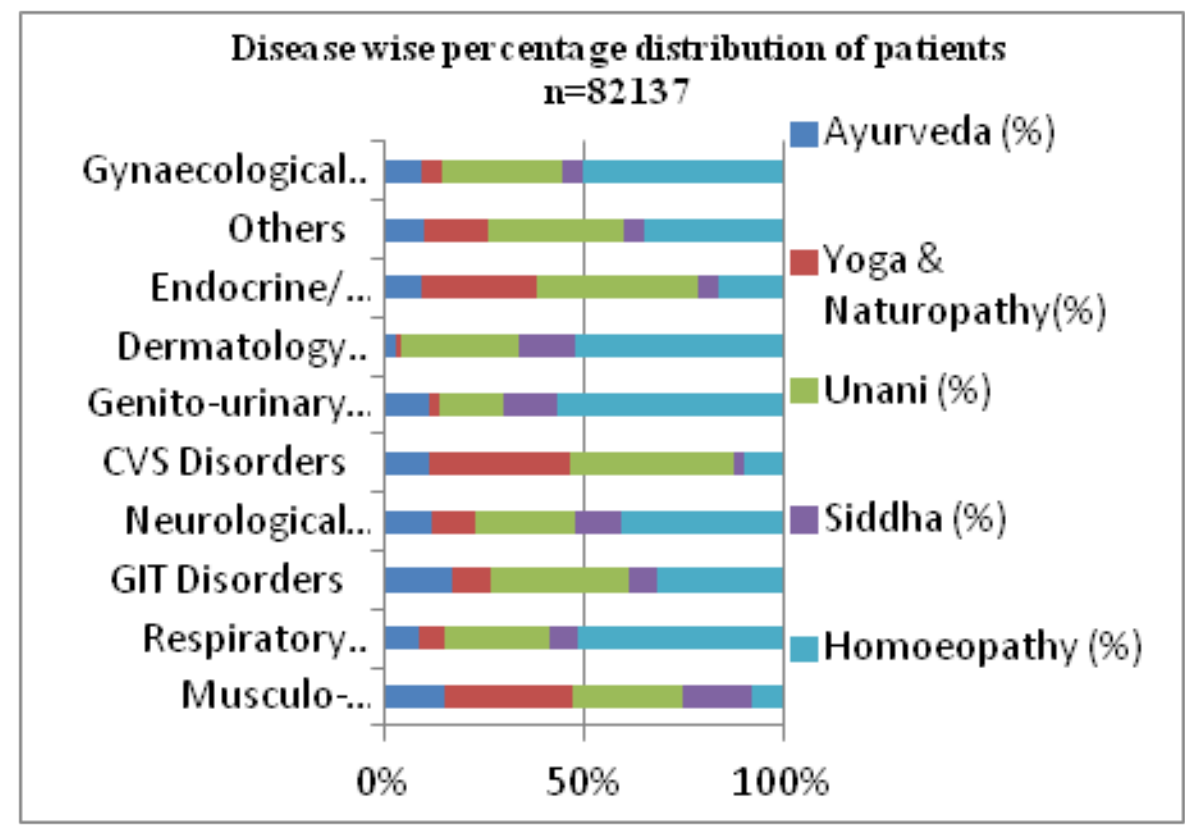

Figure 6 Disease wise percentage distribution of patients (July 20I5-January 20I8).

Table 2 Overview of Therapies done from July 2015-January 2018

\begin{tabular}{ll}
\hline Department & Total \\
\hline Ayurveda & 10577 \\
Yoga and Naturopathy & 19042 \\
Unani & 13030 \\
Sidha & 3794 \\
Grand Total & 46443 \\
\hline
\end{tabular}

*Sourced from NIC special clinic software ${ }^{5}$

Table 3 Disease wise patient distribution (July 20I5-January 20I8)

\begin{tabular}{|c|c|c|c|c|c|}
\hline Disease wise distribution & Ayurveda (\%) & $\begin{array}{l}\text { Yoga \& Naturopathy } \\
\text { (\%) }\end{array}$ & Unani (\%) & $\begin{array}{l}\text { Siddha } \\
(\%)\end{array}$ & Homoeopathy (\%) \\
\hline Musculo-skeletal Disorders & $15 \%$ & $32 \%$ & $28 \%$ & $17 \%$ & $8 \%$ \\
\hline Respiratory Disorders & $9 \%$ & $6 \%$ & $27 \%$ & $7 \%$ & $51 \%$ \\
\hline GIT Disorders & $17 \%$ & $10 \%$ & $34 \%$ & $7 \%$ & $32 \%$ \\
\hline Neurological Disorders & $12 \%$ & $11 \%$ & $25 \%$ & $12 \%$ & $40 \%$ \\
\hline CVS Disorders & $11 \%$ & $35 \%$ & $41 \%$ & $3 \%$ & $10 \%$ \\
\hline Genito-urinary Disorders & $11 \%$ & $3 \%$ & $16 \%$ & $13 \%$ & $57 \%$ \\
\hline Dermatology Disorders & $3 \%$ & $1 \%$ & $30 \%$ & $14 \%$ & $52 \%$ \\
\hline Endocrine/ Metabolic Disorders & $9 \%$ & $29 \%$ & $41 \%$ & $5 \%$ & $16 \%$ \\
\hline Others & $10 \%$ & $16 \%$ & $34 \%$ & $5 \%$ & $35 \%$ \\
\hline Gynaecological Disorders & $10 \%$ & $5 \%$ & $30 \%$ & $5 \%$ & $50 \%$ \\
\hline
\end{tabular}

*Sourced from NIC special clinic software ${ }^{5}$

\section{Services available Ayurveda}

Consultation and medicines are available along with Ayurveda therapies including- Shirodhara, Abhyanga (Sarvanga), Abhyanga (Ekanga), Patra pinda sweda (Sarvanga), Patra pinda sweda (Ekanga), Swedana (Sarvanga), Swedana (Ekanga/Nadi swedana), Akshi Tarpan, Katibasti, Grivabasti, Janubasti and Nasya.

The Ayurveda department is popular among patients for gastrointestinal diseases including hyperacidity, chronic constipation, IBS and piles; musculoskeletal diseases including osteoarthritis knee, back pain, cervical spondylosis; and Lifestyle disorders as adjuvant in diabetes \& high BP. 


\section{Yoga \& Naturopathy}

Consultation is available along with Yog Chikitsa (Asana, Pranayam, Meditation), Naturopathic diet therapy, Masso therapy (Manual full/partial), Mud therapy (Full/Partial), Steam therapy (Full/ Partial/facial), Hydrotherapy (Spinal bath, Spinal spray, Foot \& Hand, with pack, Enema), Potli/Poultice, Foot Reflexology and Mustard Pack.

The Yoga and Naturopathy department is popular among patients for Musculoskeletal diseases including back pain, cervical spondylosis, osteoarthritis knee, frozen shoulder, disc prolapsed; Endocrinological disorders including diabetes, obesity, hypothyroidism, PCOD and Respiratory diseases including Sinusitis and Bronchial asthma.

\section{Unani}

Consultation and medicines are available along with Unani therapies including Hijamat (Wet cupping), Hijamat (Dry/Gliding/ Fire cupping), Dalak, Mechanical massage chair, Mechanical riding machine, Hammam, Local massage with local steam, Facial steam, Muscle stimulation (TENS), Fasd and Takmed.

\section{Siddha}

Consultation and medicines are available along with Siddha therapies including Varmam \& Thokkanam, Thuvalai, Podi Thimiral Therapy, Vedhu, Patru, Pugai, Otradam \& Kizhi and Nasiyam.

The Unani department is popular among patients for Cardiovascular diseases High BP, dyslipidemia, coronary artery disease; Gastrointestinal diseases including chronic indigestion, liver disorders, constipation, piles; Musculoskeletal diseases including cervical spondylosis, lumbar spondylosis, osteoarthritis, rheumatoid arthritis, back pain; and Skin diseases including chronic eczema, fungal infections, cholasma, warts etc.

\section{Homoeopathy}

Consultation and medicines are available in Homoeopathic department. The department is popular among patients for Gynaecological disorders including menstrual disorders, fibromyoma uterus, polycystic ovarian disease, leucorrhoea, dysfunctional uterine bleeding, menopausal syndrome; Genito-urinary diseases including urinary tract infection, renal calculi and benign hypertrophy prostate; Skin diseases including chronic eczema, lichen planus, hair loss including alopecia areata and diffuse hair loss, chronic urticaria, ringworm, psoriasis, vitiligo; Respiratory diseases including allergic rhinitis, chronic sinusitis, chronic tonsillitis, bronchial asthma and chronic bronchitis.

\section{Collaboration of ayush systems}

AYUSH Wellness Clinic is a platform for cross-talk and collaboration between different AYUSH systems of treatment. Crossreferrals are made to achieve better and faster clinical results for the benefit of patients. Several patients have benefitted by integrating: Ayurvedic medicines \& Siddha therapies in treatment of Arthritis and Back pain; Homeopathic medicines \& Yoga in Bronchial asthma and chronic sinusitis and Unani therapy and Homoeopathic medicines in High Blood Pressure; Homoeopathic medicines \& Siddha therapies for Diffuse Hair Loss, Cervical Spondylosis and Frozen Shoulder. The physicians working at the AWC continue to collaborate for patient benefit and publish this valuable data.

AYUSH Wellness Clinic is a platform for cross-talk and collaboration between different AYUSH systems of treatment. Crossreferrals are made to achieve better and faster clinical results for the benefit of patients. Several patients have benefitted by integrating: Ayurvedic medicines \& Siddha therapies in treatment of Arthritis and Back pain; Homeopathic medicines \& Yoga in Bronchial asthma and chronic sinusitis and Unani therapy and Homoeopathic medicines in High Blood Pressure..$^{4-7}$

\section{Information, Education \& Communication (IEC)}

AWC is promoting Indian system of medicine and Homoeopathy through sustained efforts at patient communication. At the AWC, IEC material is available at a designated area near the OPD registration counter and respective pharmacies. There is also an interactive touch screen kiosk in the OPD wing. AYUSH awareness workshops are conducted at the AWC premises on yearly basis for the residents of President's Estate.

\section{AYUSH awareness workshops conducted in the year 2015}
a. Healthy Kitchen through Ayurveda
b. Naturopathic Diet and Way of Life
c. Simple cure at Home: The Unani way
d. Homeopathy for Child health

\section{AYUSH awareness workshops conducted in the year 2016}

a. Ayurveda for Life Style Disorders

b. Use and benefits of Mud Therapy (Naturopathy)

c. Menstrual Hygiene (Unani)

d. Management of Vatha Diseases through Siddha External Therapies

e. Management of Dermatological Disorders in Homeopathy

\section{AYUSH awareness workshops conducted in the year 2017}

a. Diabetes: cause, treatment and prevention through Homoeopathy \& Yoga

b. Pain management through Varmam Therapy in Siddha

c. Health benefits of Cupping Therapy: Unani

d. Preventing and treating Joint diseases through Ayurveda

\section{e. Managing Lifestyle disorders with Naturopathy}

The residents attended the workshops in large numbers and benefitted from the health information given to them. The workshop feedback was taken in form of a specially designed feedback form which was filled by $4-5$ residents after each workshop. 


\section{New initiatives in 2015}

\section{Herbal garden}

An herbal garden was planned for the clinic with support of the Horticulture department of the President's Estate. A large number of medicinal plants find place in this aesthetically designed and well maintained Herbal Garden including- Sadabahar (Catharanthus), China rose (Hibiscus rosa-sinensis), ashwagandha (Withania somnifera), Aloevera (Aloes barbadensis), Shatavari (Asparagus racemosus), Mithi tulsi (Ocimum santum), Shayama tulsi (Ocimum tenuiflorum), Dhatura (Datura stramonium), Ajwain (Trachyspermum ammi), Peepal tree (Ficus religiosa), Hadjod (Cissus quadangularis), Kacjnar (Bauhinia variegate), Patharchatta (Bryophyllum pinnatum), Pilkhan (Ficus virens), Lemongrass (Cymbopogon), Barh tree (Ficus benghalensis), Curry leaves plant (Murraya koenigii), Neem (Azadiracta indica), hldi (Curcuma longa), Safed musli(Chlorophytum borivilianum) and Pomegratnate tree (Punica granatum).

\section{Interactive touch screen Kiosk}

An interactive touch screen kiosk was put in the OPD wing of AWC. This unique kiosk was designated to inform the clinic beneficiaries about the different AYUSH systems, their strength and treatment options available. The subject matter was provided by respectice research councils and the technical support was provided by NIC.

\section{Skill development and internship programme}

Skill Development and Internship Programme was envisioned as a measure to generate awareness of AYUSH therapies and enhance the talent pool in the streams of Ayurveda, Yoga \& Naturopathy, Unani and Siddha systems of medicine. The course curriculum was and developed by physicians working at the AYUSH Wellness Clinic in collaboration with President's Secretariat. Along with different therapies done in the AYUSH system of medicine, the curriculum also included basic training in physiotherapy and First-AID. The course was conducted in the AWC premises by the physicians working at AWC, physiotherapists and First-AID experts from St. John's ambulance. So far 56 students have benefitted from this programme in five batches.

\section{New initiatives in 2016 \\ Village outreach services}

Village outreach services were started at 5 villages adopted by the Honourable President of India. Village AYUSH centres were developed by President's Secretariat at these five villages namelyAlipur, Rojka Meo, Dhaula, Harchandpur and Tajnagar located in Haryana State and regular village OPD was conducted by the physicians working at the AYUSH wellness Clinic.

\section{Festival of innovation}

AYUSH Wellness Clinic participated in the Festival of Innovation at the President's Estate, held on 12 to 19 March, 2016. Innovation at AWC showcased including:

a. Portable Shirodhara Stands that may be dismantled after use and carried in bag.

b. Induction plates for heating oil for therapy being affordable, safe and less electricity consuming than hotplates/heaters. c. Portable steam generators for steam therapy being affordable, light-weight and less electricity consuming than conventional steam apparatus.

d. Acrylic material moulds for basti therapy and modified swimming pool goggles for netra tarpan being easy to use, less time and money consuming and can be sterilized for multiple use instead of traditional Urad Dal moulds.

\section{New initiatives in 2017}

\section{New therapy additions}

To cater to the needs of patients visiting AWC, new therapies were added to the existing services in Ayurveda wing, Yoga and Naturopathy wing and Unani wing. The therapies added include- Matravasti, Churna Pinda Sweda (Sarvanga), Churna Pinda Sweda (Ekanga), Udvartan, Lepana (Ekanga) in Ayurveda wing, Hip bath in Yoga \& Naturopathy wing and Fire Cupping, Facial Cupping, and Cautery in Unani wing. The removal of warts, moles and external piles through cauterization is simple, painless OPD procedure that does not require anaesthesia or blood loss and is being well appreciated by the patients.

\section{Staff Training in first aid and CPR}

The therapists and support staffs working at AWC were trained in First-AID and CPR during the year 2017. The course was conducted in the AWC premises by First-AID experts from St. John's ambulance. Being a clinic cum therapy centre; this training was conceptualized at $\mathrm{AWC}$ as to make the employees more safety aware, spot hazards and potential incidents before they occur. First-AID and CPR training proved to be a great team building exercise. It has given employees the confidence and ability to treat themselves, their family and patients effectively in an incident, injury or illness.

\section{Research publications}

A total of 22 research papers have been published till date in peer reviewed indexed journals. Collaborative studies published include the following:

a. Success stories in form of a collection of case reports by all physicians working in the clinic.

b. A case study published on the results of integrating Unani and Ayurveda therapies and Homoeopathic medicine for the management of High Blood pressure.

c. Three clinical studies published highlighting collaborative results of combining Homoeopathic medicines \& Siddha therapies for Diffuse Hair Loss, Cervical Spondylosis and Frozen Shoulder.

\section{Future prospective}

i. Expanding therapy services to accommodate the needs of the patients and give maximum benefit at OPD level.

ii. Furthering the scope of AYUSH awareness workshops by conducting group health talks for smaller gender/age specific groups for better engagement, understanding and patient benefit. For example health talk on menstrual hygiene for pubertal girls, antenatal care for pregnant women and their attendants, managing exam stress for students etc.

iii. Addition of counselling services for patients and their attendants with special focus on mental health. 
iv. Starting an AYUSH library facility at the premises which will include general interest books as well as journals on AYUSH system of medicine.

v. Patient feedback form for constant feedback and suggestions from clinic beneficiaries.

vi. Continued focus on publication both individually and as a collaborative team effort by the physicians working at $\mathrm{AWC}^{4}$.

\section{Conclusion}

AWC is a successful model of patient-centered care and patient empowerment that is being replicated in various government departments nationwide.

\section{Acknowledgements}

None.

\section{Conflict of interest}

Author declares that there is no conflict of interest.

\section{References}

1. http://pib.nic.in/newsite/PrintRelease.aspx?relid=123676

2. http://pib.nic.in/newsite/PrintRelease.aspx?relid=123746

3. Bakshi A, Thakur T, Hasan I, et al. Model AYUSH Wellness Clinic at President's Estate, India. Indian Journal of Research. 2017;4(5):120 122.

4. Bakshi A, Thakur T, Hasan I, et al. Annual report 2017- Model AYUSH Wellness Clinic at President's Estate, India. IAJPS. 2018;05(01):567571 .

5. http://164.100.23.71/ayush/ViewCardRegistrationsReport.aspx

6. https://www.scribd.com/document/366097492/model-ayush-wellnessclinic-at-president-s-estate-india-success-stories.

7. https://www.worldwidejournals.com/paripex/recent_issues_pdf 